\title{
INCIDÊNCIA DE ACIDENTES DE TRABALHO RELACIONADA COM A NÃO UTILIZAÇÃO DAS PRECAUÇÕES UNIVERSAIS*
}

\author{
Márcia de Souza** \\ Lucila A. C. Vianna***
}

\begin{abstract}
RESUMO: Entrevistados todos (57) os funcionários do serviço de enfermagem de um hospital geral governamental de São Paulo, que sofreram acidentes de trabalho relacionados a materiais pérfuro-cortantes, ou que tiveram contato com sangue ou fluidos corpóreos contaminados no período de janeiro a setembro de 1992. Desses, $15,8 \%$ (9) eram enfermeiras, $49,1 \%$ (28) auxiliares de enfermagem, $33,3 \%$ (19) atendentes de atendentes de enfermagem e 1,8\% (1) escriturária, que apresentavam idade inferior a 40 anos. $66,1 \%$ possuíam $2^{\circ}$ grau completo ou superior e entre 4 a 7 anos de experiência na função. Em relação ao turno de trabalho, $49,1 \%$ dos acidentes ocorreram pela manhã e $38,7 \%$ durante a noite, principalmente no Pronto Socorro $(36,8 \%)$. Materiais pérfuro-cortantes foram responsáveis por $71,9 \%$ dos acidentes, sendo $75,0 \%$ entre os auxiliares de enfermagem. Os funcionários acidentados atribuíram a causa do acidente: à fatalidade, ao descuido ou imprudência da equipe médica e ao reencape de agulhas. Quanto às consequências, $57,0 \%$ dos acidentados por respingo de secreção nos olhos desenvolveram conjuntivite e uma das funcionárias, Hepatite B. Este estudo mostrou que $78,1 \%$ dos acidentes poderiam ter sido evitados, $57,0 \%$ apenas com o uso das Precauções Universais.
\end{abstract}

ABSTRACT: We interviewed every (57) nursing workers of a Govemmental General Hospital from São Paulo, that had suffered occupational accidents regarding the sharp objects or had had exposure to infectious blood or body fluids since January to September 1992. There were $15,8 \%$ (9) nurses. $49,1 \%$ (28) auxiliaries, $33,3 \%$ (19) attendants and $1,8 \%$ (1) clerks; they were younger than 40 years old. $66,1 \%$ had completed high school and they had between 4 and 7 years of experience in their function. $49,1 \%$ of the accidents occurred in the morning and $38,7 \%$ in the night. These accidents occurred mainly in the Emergency Department, with sharp objects $(36,8 \%)$; they were responsible for $71,9 \%$ of the accidents; $75,0 \%$ with the auxiliaries. These injuried workers attribute the main causes to the carelessness or imprudence of physicians or of themselves $(24,6 \%)$ and to the recapping of the needles $(19,3 \%)$. $57,0 \%$ of the injured with the sprinkling of the fluid in the eyes developed "conjunctivitis" and one of them $(1,8 \%)$ "Hepatitis B". This study showed that $78,1 \%$ of the accidents could have been avoided; $57,0 \%$ merely by the use of the Universal Precautions.

\section{INTRODUÇÃO}

O homem necessita gozar de boa saúde para garantir um trabalho condigno. Porém, em muitas atividades profissionais há maior exposição aos riscos ocupacionais e, segundo o C.D.C(6) já está demonstrado estatisticamente que o profissional de saúde está sujeito a maior número de riscos que outros

\footnotetext{
* Trabalho apresentado como tema livre no $45^{\circ}$ Congresso Brasileiro de Enfermagem. Prêmio Edith Magalhães Fráenkel, $1^{\circ}$ lugar. Recife-PE, 28 de novembro a 3 de dezembro de 1993.

** Mestranda do Curso de Enfermagem em Saúde do Adulto - EPM e Enfermeira-Chefe da Clínica de Moléstias Infecciosas do Hospital das Clínicas da PMUSP

*** Prof essora Adjunta do Departamento de Enfermagem da EPM-Doutora em Saúde Pública
} 
profissionais.

Sabe-se que o pessoal de enf ermagem representa grande parte do contingente da área da saúde. Este pessoal apresenta formação técnica heterogênea devido às diversas categorias da profissão ${ }^{(1)}$. A falta de pessoal qualificado, para assumir atividades mais complexas, predispõe os que assumem esse trabalho a uma alta sobrecarga e a um grande desgaste físico e mental, além de trabalhar em situações geradoras de tensão, sendo que a remuneração nem sempre está de acordo com as atividades exigidas.

VARGENS, ${ }^{(22)}$ cita em seu trabalho que apenas $5,6 \%$ dos enfermeiros no Brasil são do sexo masculino. Portanto, a enfermagem é exercida basicamente por mulheres, que assumem dupla jornada de trabalho decorrente de serviços domésticos e familiares, sem descanso e/ou férias. Essas premissas, segundo estudo realizado realizado por SILVA. ${ }^{(20)}$, favorecem a uma maior incidência de acidentes de trabalho entre o pessoal de enfermagem.

Em 1983, o CDC (Center for Disesase Control Atlanta, EUA) publicou um documento intitulado "Guia para Isolamento e Precauções nos Hospitais" contendo uma seção denominada "Precauções com sangue e fluidos corpóreos", recomendando aos profissionais de saúde precauções quando o paciente apresentasse suspeita ou confirmação de infecção com patógenos transmissívcis pclo sanguc. Com o advento da Síndrome da Imunodeficiência Adquirida (AIDS), o CDC publicou em 1987 "Recomendações para Prevenção da Transmissão do HIV - vírus da Imunodeficiência Humana - em profissionais da saúde" e, posteriormente em 1987, revisto e intitulado "Guia para Prevenção da Transmissão do HIV. Vírus da Hepatite B nos profissionais de saúde". (7) onde em contraste com o documento de 1983, recomenda precauções com sangue e fluidos corpóreos em $t o d o s$ os pacientes. independente do diagnóstico. Esta extensão das precauções é referida como "Precauções com Sanguc c Fluidos Corpóreos" ou simplesmentc. "Precauções Universais". considerando que todos os pacientes são potencialmente infectados pelo HIV. Hepatitc B e outros patógenos de transmissão sanguínea.

VERONESI \& FOCACCIA. ${ }^{(23)}$ salicntam a importância das precauções devido à impossibilidade de se realizar testes sorológicos para todos os pacientes que são atendidos pelos profissionais da saúde; a grande maioria dos portadores do HIV são assintomáticos (a proporção ć de 1 doentede AIDS para 10() portadores assintomáticos). Desta forma, recomen- dam que todos os indivíduos que são submetidos a exames, em que o profissional de saúde entra em contato com seu sangue ou outros fluidos orgânicos, devem ser considerados como possiveis portadores do HIV, principalmente em áreas de emergência onde o risco de contágio é maior.

Precauções Universais são preconizadas através da utilização de barreiras prara prevenção parenteral, de membranas mucosas e de exposição de pele não intacta dos profissionais da saúde, expostos ao sangue e fluidos compóreos (liquor, líquido sinovial, pleural, sêmen, secreção vaginal, líquido amniótico).

\section{As barreiras são:}

- utilização de luvas ao manipular sangue e fluidos orgânicos, mucosa ou pele com lesões, materiais contaminados e sempre que praticar punções venosas ou outros procedimentos vasculares;

- máscara e óculos protetores, sempre que houver possibilidade do procedimento gerar gotículas de sangue, ou outro fluido orgângico, que possa atingir as mucosas da boca, nariz e olhos;

- aventais, durante procedimentos que possam gerar borrifamento de sangue e/ou outros fluidos;

- lavagem das mãos imediata e intensamente sempre que em contato com sangue, ou outros fluidos orgânicos, inclusive após retirada das luvas:

- precauções para evitar ferimentos com materiais pérfuro-cortantes (agulhas, bisturis, instrumentais): não reencapar agulhas nem dobrá-las; desprezar materiais pérfuro-cortantes em recipientes de paredes rígidas e o mais próximo possível da área em que estão sendo utilizados: colocar os materiais não descartáveis $\mathrm{cm}$ recipientes apropriados, para serem levados à sala para descontaminação e esterilização. posteriormente.

Em termos de legislação brasileira, na Consolidação das Leis Trabalhistas (CLT), acidente de trabatho ć definido no artigo 19 da Lei 8213 de 24 de julho de $1991^{(5)}$. como "aquele que ocorreu pelo exercício do trabalho a serviço da empresa, provocando lesão coporal ou perturbação funcional que cause a morte, ou a perda. ou redução permanente ou temporária da capacidade para o trabalho" c consta também no inciso II do artigo 21, "acidente sof rido pelo segurado no local c no horário de trabalho em conseqüencia de: a) ato de agressão, sabotagem ou terrorismo praticado por terceiros ou companheiro de trabalho, e em c) ato de imprudência. negligência ou de imperícia de terceiros ou companheiro de trabalho". No inciso III do mesmo arigo acrescenta-se "doença proveniente de 
contaminação acidental de empregado no exercício de suas atividades".

Com base nestes aspectos legais e atuais na literatura com vastas publicações relacionadas ao assunto $(3,9,10,14)$ e na experi6encia profissional na área hospitalar, as autoras observam o alto índice de acidentes de trabalho que ocorrem em profissinonais de enfermagem que talvez pudessem ser evitados com a utilização das Precauções Universais.

Tais acidentes acarretam vários prejuízos:

- à Instituição, decorrente de sua responsabilidade legal sobre o acidente que pode ter como causa imprudência ou negligência do próprio acidentado ou de terceiros;

- aos colegas de trabalo, pois devido ao acidente pode haver licença médica, acarretando diminuição de pessoal, com conseqüente sobrecarga de serviço e,

- principalmente ao próprio funcionário, podendo ter graves conseqüências físicas e emocionais, assim aos seus familiares.

Desta forma. foram estabelecidos os seguintes objetivos para elaboração deste estudo:

$1^{\circ}$ ) verificar a incidência de acidentes de trabalho entre os profissionais de enfermagem de um hospital geral governamental;

$2^{\circ}$ ) caracterizar os profissionais acidentados com a finalidade de dar subsídios para a educação continuada;

$3^{\circ}$ )relacionar os acidentes de trabalho com a não utilização das Precauções Universais.

\section{METODOLOGIA}

A assistência de enfermagem envolve atividades de distintos graus de complexidade, o que permite ser realizada por uma equipe constituída por elementos de diferentes categorias, sob a supervisão do enfermeiro.

De acordo com a Lei $7498 / 86^{(4)}$ que dispõe sobre a Regulamentação do Exercício de Enfermagem. no parágrafo único, do artigo $2^{\circ}$ "a enfermagem é cxercida privativamente pelo enfermeiro, pelo técnico de enfermagem, pelo auxiliar de enfermagem e pela parteira, respeitados os respectivos graus de habilitação". No artigo 23 da referida Lei, é especificado que "o pessoal que se encontra executando tarefas de enfermagem, em virtude de carência de recursos hu- manos de nível médio nessa área, sem possuir formação específica regulada em lei, será autorizado, pelo Conselho Federal de Enfermagem - COFEN, a exedrcer atividades elementares de enfermagem" e, no parágrafo único do mesmo artigo, notifica-se que esta autorização somente terá validade durante 10 (dez) anos, a contar da promulgação da lei.

Desta forma, o COFEN publicou em 25 de agosto de 1987, a Resolução COFEN-91 onde dispõe sobre a autorização para a execuçào de tarefas elementares de enfermagem pelo pessoal sem formação específica regulada em lei, estabelecendo critérios para esta finalidade.

A instituição onde esta pesquisa foi realizada, não dispõe de técnicos de enfermagem no seu quadro de pessoal, assim como ainda utiliza atendentes de enfermagem; porém não houve mais contratação desde a promulgação da Lei 7498/86, sendo que os remanescentes estão sendo substituídos por auxiliares de enfermagem após demissões ou formação profissional específica, seja como auxiliar ou como enfermeiro e, exercem suas funções com a autorização necessária fornecida pelo COREN-SP.

Apesar de os escriturários não pertencerem às categorias de enfermagem, foram aqui incluídos por exercerem função sem formação específica na área. atuando diretamente com a equipe de enfermagem com atribuições simplesmente administrativas, porém na mesma área de serviço, correndo risco de acidentes como foi observado (acidentc com agulha contaminada deixada na mesa por um médico após um procedimento próximo a um prontuário por ela manipulado)

Este estudo foi realizado com 57 casos de acidentes de trabalho, ocorridos em funcionários do departamento de enfermagem de um hospital geral governamental de São Paulo, no período de janeiro a setembro de 1992.

Os dados foram obtidos através do levantamento das fichas de acidentes de trabalho ocorridos na período acima referido. Posteriormente foram entrevistados os funcionários (Anexo I), com o objetivo de complementar os dados de identificação c verificar a descrição exata do acidente e se o mesmo poderia, na opinião do acidentado, ter ou não sido evitado.

\section{As variáveis observadas foram:}

- individuais: sexo, idade, procedência, função, tempode trabalho na função por ocasião do acidente, local e turno de trabalho no momento do acidente. 
Tabela 1 - Funcionários de enfermagem, que sofreram acidentes de trabalho, de acordo com sexo e categoria profissional - Hospital Geral Govemamental, São Paulo - Janeiro a Setembro de 1992.

\begin{tabular}{|c|c|c|c|c|c|c|c|c|c|c|}
\hline \multirow[t]{3}{*}{ SEXO } & \multicolumn{10}{|c|}{ CATEGORIA PROFISSIONAL } \\
\hline & \multicolumn{2}{|c|}{ Atendente } & \multicolumn{2}{|c|}{ Auxiliar } & \multicolumn{2}{|c|}{ Enfermeira } & \multicolumn{2}{|c|}{ Escriturária } & \multicolumn{2}{|c|}{ TOTAL } \\
\hline & $\mathrm{N}$ & $\%$ & $\mathrm{~N}$ & $\%$ & $\mathrm{~N}$ & $\%$ & $\mathrm{~N}$ & $\%$ & $\mathrm{~N}$ & $\%$ \\
\hline Feminino & 12 & 63,2 & 27 & 96,5 & 9 & 100,0 & 1 & 100,0 & 49 & 86,0 \\
\hline Masculino & 7 & 36,8 & 1 & 3,5 & - & - & . & & 8 & 14,0 \\
\hline TOTAL & 19 & 100,0 & 28 & 100.0 & 9 & 100,0 & 1 & 100,0 & 57 & 100,0 \\
\hline
\end{tabular}

Tabela 2 - Faixa etária dos funcionários de enfermagem, que sofreram acidentes de trabalho, de acordo com sexo e categoria profissional - Hospital Geral Govemamental, São Paulo - Janeiro a Setembro de 1992.

\begin{tabular}{|c|c|c|c|c|c|c|c|c|c|c|}
\hline \multirow[t]{3}{*}{ FAIXA ETÁRIA } & \multicolumn{10}{|c|}{ CATEGORIA PROFISSIONAL } \\
\hline & \multicolumn{2}{|c|}{ Atendente } & \multicolumn{2}{|c|}{ Auxiliar } & \multicolumn{2}{|c|}{ Enfermeira } & \multicolumn{2}{|c|}{ Escriturária } & \multicolumn{2}{|c|}{ TOTAL } \\
\hline & $\mathrm{N}$ & $\%$ & $\mathrm{~N}$ & $\%$ & $\mathrm{~N}$ & $\%$ & $\mathrm{~N}$ & $\%$ & $\mathrm{~N}$ & $\%$ \\
\hline 20 a 24 & - & - & 1 & 3,6 & - & $\ldots$ & & 100,0 & 2 & 3,5 \\
\hline 25 a 29 & 4 & 21,0 & 5 & 17,8 & 5 & 55,6 & & - & 14 & 24,6 \\
\hline 30 a 34 & 1 & 5,3 & 7 & 25,0 & 3 & 33,3 & & - & 11 & 19,3 \\
\hline 35 а 39 & 10 & 52,6 & 5 & 17,8 & 1 & 11,1 & & - & 16 & 28,1 \\
\hline 40 a 44 & 1 & 5,3 & 4 & 14,3 & - & - & & - & 5 & 8,8 \\
\hline 45 a 49 & 1 & 5,3 & 2 & 7,1 & - & - & & - & 3 & 5,3 \\
\hline 50 a 54 & 2 & 10,5 & 4 & 14,3 & - & - & & - & 6 & 10,5 \\
\hline TOTAL & 19 & 100,0 & 28 & 100,0 & 9 & 100,0 & & 100,0 & 57 & 100,0 \\
\hline
\end{tabular}

- em relação ao acidente: objeto causador, modo ou como ocorreu, e o motivo do acidente, na opinião dos acidentados.

Foram levantadas 147 fichas das quais 73 não foram consideradas por estarem relacionadas a traumas (ex: problemas de coluna, devido à mecânica corporal no transporte de pacientes, quedas em escadas ou pisos escorregadios e, acidentes em trânsito a caminho do hospital).

Das 74 fichas restantes, todas relacionadas aos acidentes com materiais pérfuro-cortantes ou respingos de sangue e/ou secreções, somente foi possível entrevistar 57 funcionários (no período de setembro a outubro de 1992). Dos 17 que não forma entrevistados, dez estavam em férias, seis eram demissionários e um funcionário estava em licença médica prolongada devido a hepatite $\mathrm{B}$.

Em setembro de 1992, o quadro de pessoal de enfermagem na instituição em estudo era de 248 enfermeiros (16,2\%), 626 auxiliares de enfermagem $(40,9 \%), 590$ atendentes de enfermagem $(38,6 \%)$ e de 65 escriturários $(4,2 \%)$. perfazendo um total de 1529 funcionários.

\section{RESULTADOS}

Na Tabela 1, observa-se a predominância acentuada do sexo feminino entre o pessoal que trabalhava na área da enfermagem. Também verifica-se a maior incidência dos acidentes entre os auxiliares de enfermagem, podendo estar associado ao fato deste grupo apresentar atribuições relacionadas diretamente com materiais pérfuro-cortantes (preparo e administração de medicamentos).

Na Tabela 2, nota-se uma maior concentração de pessoal na faixa de 35 a 40 anos, sendo que a maioria dos enfermeiros encontra-se entre 25 e 30 anos. E aproximadamente $77,0 \%$ dos funcionários acidentados têm menos de 40 anos de idade, o que confirma os resultados de SILVA, (20) a qual salienta em seu trabalho. que os profissionais de enfermagem são relativamente jovens, em período fértil; e, segundo a mesma autora. quanto menor a idade. menor é a oportunidade de seu preparo

Na Tabela 3 verifica-se a predominância daqueles procedentes da região sudeste, principalmente de São Paulo e em seguida, daqueles procedentes de Minas Gerais e do Rio de Janeiro. Entre as enfermeiras a distribuição foi eqüitativa entre São Paulo e Rio 
Tabela 3 - Procedência dos funcionários de enfermagem, que sofreram acidentes de trabalho, de acordo com sexo e categoria profissional - Hospital Geral Governamental, São Paulo - Janeiro a Setembro de 1992.

\begin{tabular}{|c|c|c|c|c|c|c|c|c|c|c|}
\hline \multirow[t]{3}{*}{ PROCEDÊNCIA } & \multicolumn{10}{|c|}{ CATEGORIA PROFISSIONAL } \\
\hline & \multicolumn{2}{|c|}{ Atendente } & \multicolumn{2}{|c|}{ Auxiliar } & \multicolumn{2}{|c|}{ Enfermeira } & \multicolumn{2}{|c|}{ Escriturária } & \multicolumn{2}{|c|}{ TOTAL } \\
\hline & $\mathrm{N}$ & $\%$ & $\mathrm{~N}$ & $\%$ & $\mathrm{~N}$ & $\%$ & $\mathrm{~N}$ & $\%$ & $\mathrm{~N}$ & $\%$ \\
\hline Sâo Paulo & 13 & 68,4 & 12 & 42,9 & 3 & 33,3 & - & $\ldots$ & 28 & 49,1 \\
\hline Minas Gerais & 4 & 21,1 & 4 & 14,3 & 1 & 11,1 & - & & 9 & 15,8 \\
\hline Rio de Janeiro & - & - & 3 & 10,7 & 3 & 33,3 & - & & 6 & 10,5 \\
\hline Pernambuco & - & - & 3 & 10,7 & - & & - & & 3 & 5,3 \\
\hline Outros Estados" & 2 & 10,5 & 6 & 21,4 & 2 & 22,3 & 1 & 100,0 & 11 & 19,3 \\
\hline TOTAL & 19 & 100,0 & 28 & 100,0 & 9 & 100,0 & 1 & 100,0 & 57 & 100,0 \\
\hline
\end{tabular}

Tabela 4 - Grau de instrução dos funcionários de enfermagem, que sofreram acidentes de trabalho, de acordo com sexo e categoria profissional - Hospital Geral Governamental, São Paulo - Janeiro a Setembro de 1992.

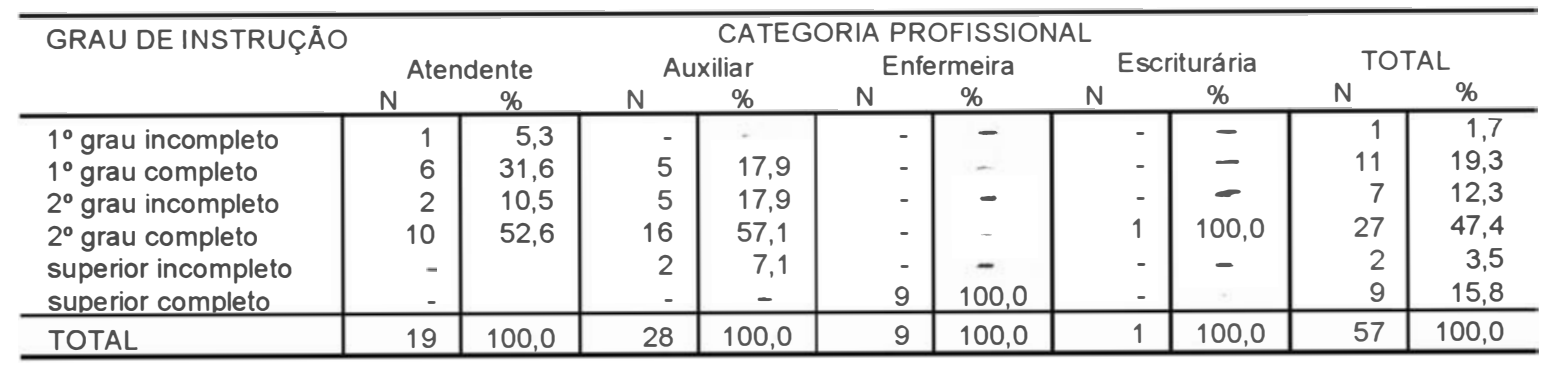

de Janeiro (33,3\%); já os auxiliares e atendentes eram principalmente procedentes de São Paulo c de Minas Gerais.

Observa-se na Tabela 4, a percentagem elevada de funcionários com o $2^{\circ}$ grau de instrução completo $(47,4 \%)$. Para os enfermeiros, há necessidade do superior completo; no entanto para os demais profissionais, o pré-requisito é apenas o $1^{\circ}$ grau. Apesar da não tabulação, observou-se um grande número de atendentes que estão fazendo o curso de auxiliar de enfermagem, assim como, os dois casos de auxiliares de enfermagem que estão cursando a graduação (superior incompleto).

Desta forma, nota-se além do esforço em progredir profissionalmente, uma sobrecarga de atividades: estudo e trabalho.

Na Tabela 5, destaca-se a percentagem de $26,3 \%$ dos funcionários acidentados com tempo de trabalho na função entre 4 e 7 anos, sendo que $55.6 \%$ das enfermeiras estavam nesta faixa. A maioria dos auxiliares de enfermagem não tinham um ano de experiência na função na ocasião do acidente.

Os turnos de trabalho na enfermagem hospitalar são obrigatórios para manutenção da assistência nas
24 horas do dia ininterruptamente. SILVA, ${ }^{(20)}$ salienta que as alterações de turno c. principalmente o trabalho à noite. trazem altcrações fisiológicas, interferem no sono c repouso, no lazer, prejudicando o relacionamento social e familiar.

Geralmente é opção do funcionário trabalhar no horário da noite, com o objetivo de melhorar o scu orçamento (adicional noturno). como também poder ter outra fonte de renda, ou mesmo estudar. Um trabalho realizado nos Estados Unidos da América (18) demonstra que o maior número de acidentes na enfermaria ocorrem à noite.

$\mathrm{Na}$ Tabela 6, observa-se uma porcentagem maior no turno da manhã, porém não se pode ignorar o fato de se ter um maior número de procedimentos e concentração de profissionais neste horário. Entre as enfermeiras, $66,7 \%$ dos acidentes ocorreram à noite.

A Tabela 7 mostra a alta incidência de acidentes no Pronto Socorro (PS): vale salientar que o PS da instituição pesquisada contém várias especialidades e atende a grande demanda. No mês de agosto de 1992. por exemplo, foram atendidos 27.921 pacientes com as mais diversas patologias. Considerando PS e UTI setores de emergência/urgência, que requerem maior 
Tabela 5 - Tempo na função exercida pelos funcionários de enfermagem, que sofreram acidentes de trabalho, de acordo com sexo e categoria profissional - Hospital Geral Governamental, São Paulo - Janeiro a Setembro de 1992.

\begin{tabular}{|c|c|c|c|c|c|c|c|c|c|c|}
\hline \multirow{3}{*}{$\begin{array}{l}\text { TEMPO NA FUNÇĀO } \\
\text { (anos) }\end{array}$} & \multicolumn{10}{|c|}{ CATEGORIA PROFISSIONAL } \\
\hline & \multicolumn{2}{|c|}{ Atendente } & \multicolumn{2}{|c|}{ Auxiliar } & \multicolumn{2}{|c|}{ Enfermeira } & \multicolumn{2}{|c|}{ Escriturária } & \multicolumn{2}{|c|}{ TOTAL } \\
\hline & $\mathrm{N}$ & $\%$ & $\mathrm{~N}$ & $\%$ & $\mathrm{~N}$ & $\%$ & $\mathrm{~N}$ & $\%$ & $\mathrm{~N}$ & $\%$ \\
\hline-1 & - & - & 6 & 21,1 & 1 & 11,1 & - & - & 7 & 12,3 \\
\hline $1-3$ & 1 & 5,3 & 5 & 17,9 & 3 & 33,3 & - & - & 9 & 15,8 \\
\hline $4-7$ & 6 & 31,6 & 3 & 10,7 & 5 & 55,6 & 1 & 100,0 & 15 & 26,3 \\
\hline $7-9$ & 1 & 5,3 & 5 & 17,9 & - & 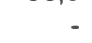 & - & - & 6 & 10,5 \\
\hline $10-12$ & 6 & 31,8 & 4 & 14,3 & - & - & - & - & 10 & 17,5 \\
\hline $13-15$ & 3 & 15,8 & - & - & - & - & - & - & 3 & 5,3 \\
\hline $16-18$ & 1 & 5,3 & 4 & 14,3 & - & - & - & - & 5 & 8,8 \\
\hline $19-21$ & 1 & 5,3 & 1 & 3,6 & - & - & - & - & 2 & 3,5 \\
\hline TOTAL & 19 & 100,0 & 28 & 100,0 & 9 & 100,0 & 1 & 100,0 & 57 & 100,0 \\
\hline
\end{tabular}

Tabela 6 - Turno de trabalho dos funcionários de enfermagem, que sofreram acidentes de trabalho, de acordo com sexo e categoria profissional - Hospital Geral Governamental, São Paulo - Janeiro a Setembro de 1992.

\begin{tabular}{|c|c|c|c|c|c|c|c|c|c|c|}
\hline \multirow[t]{3}{*}{ TURNO } & \multicolumn{10}{|c|}{ CATEGORIA PROFISSIONAL } \\
\hline & \multicolumn{2}{|c|}{ Atendente } & \multicolumn{2}{|c|}{ Auxiliar } & \multicolumn{2}{|c|}{ Enfermeira } & \multicolumn{2}{|c|}{ Escriturária } & \multicolumn{2}{|c|}{ TOTAL } \\
\hline & $\mathrm{N}$ & $\%$ & $\mathrm{~N}$ & $\%$ & $\mathrm{~N}$ & $\%$ & $\mathrm{~N}$ & $\%$ & $\mathrm{~N}$ & $\%$ \\
\hline Manhå & 10 & 52,6 & 14 & 50,0 & 3 & 33,3 & 1 & 100,0 & 28 & 49,1 \\
\hline Tarde & 1 & 5,3 & 6 & 21,4 & - & & - & - & 7 & 12,3 \\
\hline Noite & 8 & 42,1 & 8 & 28,6 & 6 & 66,7 & - & - & 22 & 38,6 \\
\hline TOTAL & 19 & 100,0 & 28 & 100,0 & 9 & 100,0 & 1 & 100,0 & 57 & 100,0 \\
\hline
\end{tabular}

rapidez e presteza na execução das atividades, conseqüentemente, é onde ocorre maior risco de acidentes.

Também na Tabela 7, destaca-se a Neurologia entre as clínicas especializadas por ter apresentado elevado índice de acidentes (14,0\%). Segundo os funcionários dessa unidade, este resultado é devido principalmente, à sobrecarga de atividades requeridas pelos pacientes em estado grave que ali se concentram.

Relacionando o setor com o turno onde ocorreu o acidente, destacam-se os acidentes no PS, durante o turno da noite, apesar de o maior número dos casos atendidos pela manhã (entre 9 e 11 horas): porém, durante a noite são de maior gravidade. Na UTI, apesar dc a gravidade dos pacientes não se alterar em decorrência dos turnos, houve maior número de acidentes à noite $(22.7 \%)$.

Vários autores, FURTH( ${ }^{(9)}$, JAGGER ${ }^{(10)} \mathrm{e}$ MBELL ${ }^{(13)}$, demonstraram a alta incidência de acidentes de trabalho com materiais pérfuro-cortantes (agulha, escalpe, lâmina de bisturi, de gilcte, de barbear, alfinete). Neste estudo encontrou-se também agulhas e escalpes como causadores de $52,2 \%$ de todos os acidentes.

\section{4 - DISCUSSÃO}

Anualmente mais de 12.000 profissionais da saúde dos EUA adquirem Hepatite B durante a assistência ao doente ${ }^{(16)}$ e, destes cerca de 250 morrem em decorrência de problemas hepáticos. Estima-se que mais de 2.000 picadas com agulhas contaminadas ocorrem por dia somente nos EUA. Neste estudo, observou-se um caso de Hepatite B adquirido por acidente com agulha contaminada.

A probabilidade de soroconversão para a AIDS em relação à Hepatite $\mathrm{B}$ é baixa - cerca de $0,5 \%$ por exposição, contra $30,0 \%$ respectivamente $(17,19,2)$. Porém, desde 1984 já existem casos relatados na literatura científica, de profissionais da saúde que se contaminaram com HIV e desenvolveram posteriormentc AIDS. sem terem apresentado outra forma de contágio que não tenha sido durante o exercício da profissão.

O CDC relatou em 1988. 19 casos de profissionais da saúde que se contaminaram com o HIV durante suas funções, em diferentes localidades (ANE$\mathrm{XO}$ 2) sendo seis enfermeiras, das quais quatro se contaminaram por picada de agulha e duas por exposição membrano-mucosa. 
Tabela 7 - Setor de trabalho dos funcionários de enfermagem, que sofreram acidentes de trabalho, de acordo com sexo e categoria profissional - Hospital Geral Governamental, São Paulo - Janeiro a Setembro de 1992.

\begin{tabular}{|c|c|c|c|c|c|c|c|c|c|c|}
\hline \multirow[t]{3}{*}{ SETOR } & \multicolumn{10}{|c|}{ CATEGORIA PROFISSIONAL } \\
\hline & \multicolumn{2}{|c|}{ Atendente } & \multicolumn{2}{|c|}{ Auxiliar } & \multicolumn{2}{|c|}{ Enfermeira } & \multicolumn{2}{|c|}{ Escriturária } & \multicolumn{2}{|c|}{ TOTAL } \\
\hline & $\mathrm{N}$ & $\%$ & $\mathrm{~N}$ & $\%$ & $\mathrm{~N}$ & $\%$ & $\mathrm{~N}$ & $\%$ & $\mathrm{~N}$ & $\%$ \\
\hline Pronto Socorro & 8 & 42,1 & 11 & 39,3 & 2 & 22,2 & - & - & 21 & 36,8 \\
\hline UTI & 3 & 15,8 & 1 & 3,6 & 4 & 44,5 & - & - & 8 & 14,0 \\
\hline C. Gerais & - & & 7 & 25,0 & - & - & 1 & 100,0 & 8 & 14,0 \\
\hline C. Especializadas & 4 & 21,0 & 2 & 7,1 & 3 & 33,3 & - & - & 9 & 15,8 \\
\hline Ambulatório & - & - & 2 & 7,1 & - & - & - & - & 2 & 3,6 \\
\hline Neurologia & 3 & 15,8 & 5 & 17,9 & - & - & - & - & 8 & 14,0 \\
\hline Radiologia & 1 & 5,3 & - & - & - & - & - & - & 1 & 1.8 \\
\hline TOTAL & 19 & 100,0 & 28 & 100,0 & 9 & 100,0 & 1 & 100,0 & 57 & 100,0 \\
\hline
\end{tabular}

Tabela 8 - Setor em relação ao turno de trabalho dos funcionários de enfermagem, que sofreram acidentes de trabalho, de acordo com sexo e categoria profissional - Hospital Geral Governamental, São Paulo - Janeiro a Setembro de 1992.

\begin{tabular}{|c|c|c|c|c|c|c|c|c|}
\hline \multirow[t]{3}{*}{ SETOR } & \multicolumn{8}{|c|}{ CATEGORIA PROFISSIONAL } \\
\hline & \multicolumn{2}{|c|}{ Atendente } & \multirow{2}{*}{$\begin{array}{c}\text { Auxiliar } \\
\mathrm{N}\end{array}$} & \multicolumn{2}{|c|}{ Enfermeira } & \multirow{2}{*}{$\begin{array}{l}\text { Escriturária } \\
\%\end{array}$} & \multirow{2}{*}{\multicolumn{2}{|c|}{$\begin{array}{r}\text { TOTAL } \\
\%\end{array}$}} \\
\hline & $\mathrm{N}$ & $\%$ & & $\%$ & $\mathrm{~N}$ & & & \\
\hline Pronto Socorro & 8 & 28,6 & 2 & 28,6 & 11 & 50,0 & 21 & 36,8 \\
\hline UTI & 2 & 7,1 & 1 & 14,3 & 5 & 22,7 & 8 & 14,0 \\
\hline C. Gerais & 6 & 21,4 & 1 & 14,3 & 1 & 4,5 & 8 & 14,0 \\
\hline C. Especializadas & 6 & 21,4 & - & - & 3 & 13,6 & 9 & 15,8 \\
\hline Ambulatório & 2 & 7,1 & - & - & - & - & 2 & 3,5 \\
\hline Neurologia & 4 & 14,3 & 2 & 28,6 & 2 & 9,1 & 8 & 14,0 \\
\hline Radiologia & 2 & - & 1 & 14,3 & - & - & 1 & 1,8 \\
\hline TOTAL & 28 & 100,0 & 7 & 100,0 & 22 & 100,0 & 57 & 100,0 \\
\hline
\end{tabular}

MBELL, (13) observou que a utilização das Precauções Universais é negligente, onde a incidência de pacientes portadores do HIV é baixa. Afirma ainda que o risco da contaminação depende da prevalência da infecção no paciente e da frequência de exposições. Até o momento deste estudo, não havia casos de acidentes e contaminação por HIV relatados pelo Ministério

entrevistados continuam com acompanhamento sorológico periódico.

O contágio acidental é relativamente raro entre os profissionais da saúdc. desde que adotem as recomendações específicas para prevenção de acidentes $^{(23)}$.

Apesar de existir alguns artigos que questionam as Precauções Universais. como o de MANIAN (11), considera-se necessário constante treinamento, com orientação em serviço, com o objetivo da conscientização geral da necessidade do uso de tais precauções. evitando maiores consequências a todos os trabalhadores que atuam na área da saúde ${ }^{(8)}$.
Os casos relatados envolvendo secreções, o foram por rcspingos nos olhos (secreção traqueal) durante aspiração de secreção e/ou tosse do paciente. Acidentes com presença de sangue ocorreram durante execução de curativos: um caso em que a luva cirúrgica continha microfuros; outro em que, ao ser retirado o catéter venoso, houve respingo de sangue nos olhos da funcionária: e um terceiro em que , ao ser realizado enteroclisma em paciente com enterorragia, este se agitou, batendo na comadre e conseqüentemente houve respingos na face (olhos e mucosa oral)da funcionária. Os acidentes relacionados com solução química ocorreram durante o processo de lavagem c/ou descontaminação de materiais contaminados.

Quanto aos motivos dos acidentes ocorridos entre os funcionários pesquisados. os atendentes alegaram ter sido "por acidente", "não tinham como evitar" c que "o acidente foi por causa da agitação do paciente". Entre os auxiliares de enfermagem o maior motivo apontado foi por "reencape de agulha" (35,7\%). Já entre as enfermeiras, o motivo principal citado foi a "pressa, o cansaço. o excesso de serviço, descuido 
Tabela 9 - Causa de acidentes de trabalho entre os funcionários de enfermagem, que sofreram acidentes de trabalho, de acordo com sexo e categoria profissional - Hospital Geral Governamental São Paulo - Janeiro a Setembro de 1992.

\begin{tabular}{|c|c|c|c|c|c|c|c|c|c|c|}
\hline \multirow[t]{3}{*}{ CAUSA } & \multicolumn{10}{|c|}{ CATEGORIA PROFISSIONAL } \\
\hline & \multicolumn{2}{|c|}{ Atendente } & \multicolumn{2}{|c|}{ Auxiliar } & \multicolumn{2}{|c|}{ Enfermeira } & \multicolumn{2}{|c|}{ Escriturária } & \multicolumn{2}{|c|}{ TOTAL } \\
\hline & $\mathrm{N}$ & $\%$ & $\mathrm{~N}$ & $\%$ & $\mathrm{~N}$ & $\%$ & $\mathrm{~N}$ & $\%$ & $\mathrm{~N}$ & $\%$ \\
\hline $\begin{array}{l}\text { Material } \\
\text { pérfuro-cortantes } \\
\text { ecreçăo } \\
\text { Sangue } \\
\text { Soluçăo Química } \\
\text { Ampola }\end{array}$ & $\begin{array}{r}11 \\
5 \\
- \\
2 \\
1\end{array}$ & $\begin{array}{r}59,9 \\
26,3 \\
\\
10,5 \\
5,3 \\
\end{array}$ & $\begin{array}{r}23 \\
1 \\
1 \\
1 \\
2\end{array}$ & $\begin{array}{r}82,1 \\
3,6 \\
3,6 \\
3,6 \\
7,1\end{array}$ & $\begin{array}{l}6 \\
1 \\
2 \\
- \\
-\end{array}$ & $\begin{array}{l}66,7 \\
11,1 \\
22,2\end{array}$ & . & $\begin{array}{r}100,0 \\
- \\
- \\
- \\
-\end{array}$ & $\begin{array}{r}41 \\
7 \\
3 \\
3 \\
3\end{array}$ & $\begin{array}{r}71,8 \\
12,3 \\
5,3 \\
5,3 \\
5,3\end{array}$ \\
\hline TOTAL & 19 & 100,0 & 28 & 100,0 & 9 & 100,0 & 1 & 100,0 & 57 & 100,0 \\
\hline
\end{tabular}

c negligência da equipe médica". Uma delas relacionou agulhas $\mathrm{c}$ lâminas de bisturi deixadas por médicos após algum procedimento, em geral no meio de campos ou sobre a mesa.

Também foram relatados: falta de dispositivo para descarte de materiais pefuro-cortantes próximo ao local de uso (no PS); aparelhos de tricotomia inadequados: c. luvas com presença de microfuros.

\section{CONCLUSÕES E CONSIDERAÇÕES FINAIS}

Dos 57 funcionários do serviço de enfermagem de um hospital geral gov crnamental de São Paulo, que sofreram acidentes de trabalho relacionados a matcriais pérfuro-cortantes. ou tiveram contato com sangue ou fluidos corpórcos contaminados no período de janeiro a setembro de $1992,15.8 \%$ cram enfemiciras. $49.1 \%$ auxiliares de enfermagem. $33.3 \%$ atendentes e uma cscriturária. Apresentavam idade abaixo de 4) anos; $66,1 \%$ possuíam $2^{\circ}$ grau completo $\mathrm{c}$ entre + a 7 anos de cxperiência na função.

Em relação ao turno de trabalho, $49.1 \%$ dos acidentcs ocorreram pela manhã e $38,8 \%$ durante a noite, principalmente no Pronto Socorro (36.8\%). Matcriais pefuro-cortantes foram responsáveis por $71.9 \%$ dos acidentes. sendo $75,0 \%$ entre os auxiliares de enfermagcm. Os funcionários acidentados atribuíram a causa do acidente: à fatalidade, ao descuido ou impnudência da equipe médica e ao recncape de agulhas.

Quanto às consequências. $57.0 \%$ dos acidentados. por respingo de secreção nos olhos. desenvolveram conjuntivite $\mathrm{c}$ uma das funcionárias, Hepatite $\mathrm{B}$.

Estc cstudo mostrou que $78,1 \%$ dos acidentes poderiam ser cvitados: $57,(0 \%$. apenas com o uso adequado das Precauçõcs Universais. através da utilização de luvas. óculos c principalmente com descartc apropriado de matcriais pefuro-cortantes. Todos os funcionários acidentados continuam com acompanhamento sorológico periódico

\section{REFERÊNCIAS BIBLIOGRÁFICAS}

1. ALMEIDA. M.C.P. Processo e divisão do trabal ho na enfermagem. Tema oficial do .XXIX Congresso Brasileiro do enfermagem. Salvador/BA. 1986

2. ANONYMOIS. Needlestich transmission of HITI,V III from a patient infected in Africal. lancet 2: 1376. 1984

3. BEEKMANN, S.A. et al. Risky business: using necessarily imprecise casuality counts to estimate occupational rish for HIV-1 infection. Infec ('ontrol Hosp. epudemal 11 : $371-9,1990$.

4. BRASII. Leis, decretos. etc. Decreto n"94406 de 8 de junho de 1987. Diarro Oficial. Brasilia 9 de junho de $1987 \mathrm{p}$. 8853-5, regulamenta a l cei n" 7498 de 25 de junho de 1986 que dispòe sobre o exercicio da enfermagem e da outras providencias.

5. CAMPANIIOLE, A. $85^{\circ}$ Consolidação das I cis Traballhistas e Legislação Complementar. São Paulo: Atlas. 1991.
6. CENTIER FOR IOISIAASI: CONTROI. Recomendations for prevention of IIIV transmission in health-care settings. MMW'R 1987; 36 (Sup. 2)

7. CI:NTIER FOR DISI:ASI: C'ONIJTROI.. I!pdate: Acquired Immunodeliciency Syndrome and human ciency virus and Hepatits 13 Virus to health-care and public-saliety worhers. MNW'R

8. VI)M(ONI) M. et al. ElYect of bedside needle disposal units on necdle recapping frepuency and nesdlestick injury. Infect ('ontrol Hosp. Fiplemiol 1988: 9: 114-6.

९. FIRTII, P.A. Acquired Immunodeliciency Syndromo (AIISS) as an (Jccupational I)iscasc. Annals of International Medicine 1988, 108, p. 156.

10. JAGGER, I. et al. Rates of needlestick injury eaused by various devices in a university hospital. The New England Journal of Medicine. 319)(5), 284-8. 1988. 
11. MANIAN, F.A. Universal Precautions "Clarified"? Infect Control Hosp. Epidemiol 9 (8) 343-4. 1988.

12. MARCUS, R. Cooperative Needlestick Surveillance Group Surveillance of health care workers exposed to blood from patientx with HIV. N. England J Med 1988; 319; 1118-23.

13. MBELL, D. HIV transmission in health care settings: risk and risk reduction. The American JMed 91, s.3B; 294-95.

14. MCEVOY, M. Prospective study of clinical, laboratory and ancillary staff with accidental exposures to blood or body fluids from patients infected with HIV. Br Med J. 294, p.1595-97. 1987.

15. MCGRAY, E. Cooperative needlestick surveillance group. Occupational risk of the AIDS among health care workers. NEngl J Med 1986; 314: 1127-32.

16. MORGAN, D. HIV and needlestick in juries. Lancet 1990335 (5), n 1280

17. NEISSON-VERNANT, C. et al. Needlestick HIV seroconversion in a nurse. Lancet, 2: 814. 1986.
18. NEUBERGER, J. \& HARTLEY, S. Occupational safety and health issues affect registered nurses. Occupational Health \& Safety 1988, 9: 25-27.

19. OKSENHENDLER; E. et al. HIV infection with seroconversion after superficial needlestick in jury to the finger. The N. Eng. J. of Med. 1986, 315 (9) 582.

20. SILVA, V.E.F. Estudo sobre acidentes de trabalho ocorridos com trabalhadores de enfermagem de um hospital de ensino. Dissertação de mestrado apresentada a EEUSP. São Paulo, 1988. 176p.

21. STRICOF, R.L. et al. HTLVII/LAV seroconversion following a deep intramuscular needlestick injury. The N. Eng. J. Med. 1986314 (17), 1115.

22. VARGENS, O. M.C. O homem enfermeiro e sua opção pela enfermagem. Dissertaçào de mestrado apresentada a EEUSP. São Paulo, 1989.

23. VERONESI, R. \& FOCACCIA, R. AIDS entre os profissionais da sauide: riscos e prevenção. Rev Bras. Clin. Terap. 13 (4), 130-2. 1989.

Recebido para publicação em 28.11.93 


\section{ANEXO I}

PROTOCOLO

\section{INCIDÊNCIA DE ACIDENTES DE TRABALHO RELACIONADOS COM A NÀO UTILIZAÇÃO DAS PRECAUÇÕES UNIVERSAIS}

\section{IDENTIFICAÇÃO}

sexo:

idade:

grau de escolaridade:

procedência:

flonção cupação:

há quanto tempo na função:

turno de trabalho:

atribuições relacionadas ao acidente:

\section{ACIDENTE:}

Clínica:

O que causou o acidente?

Como ocorreu?

Em sua opinião, por que ocorreu?

Houve consequiências? Quais? 


\section{ANEXO 2}

Table 2 - HIV-infected health-care workers with no reported nonoccupational risk factors and for whom case histories have been published in the scientific literature

\section{Cases with Documented Seroconversion}

$\begin{array}{cll}\text { Case } & \text { Occupaation } & \text { Country } \\ 1^{\star} & \text { NS } & \text { United States } \\ 2 & \text { NS } & \text { United States } \\ 3 & \text { NS } & \text { United States } \\ 4 & \text { NS } & \text { United States } \\ & & \\ 5 & \text { NS } & \text { United States } \\ 6 & \text { Nurse } & \text { England } \\ 7 & \text { Nurse } & \text { France } \\ 8 & \text { Nurse } & \text { Martinique } \\ 9 & \text { Research Lab } & \text { United States } \\ & \text { worker } & \\ 10 & \text { Home healthcare } & \text { United States } \\ & \text { Worker } & \\ 11 & \text { NS } & \text { United States } \\ 12 & \text { Phlebotomist } & \text { United States } \\ 13 & \text { Technologist } & \text { United States } \\ 14 & \text { NS } & \text { United States } \\ 15 & \text { Nurse } & \text { Italy } \\ 16 & \text { Nurse } & \text { France } \\ 17 & \text { Navy medic } & \text { United States } \\ 18 & \text { Clinical lab worker } & \text { United States }\end{array}$

Type of Exposure

Needlestick

Needlestick

Needlestick

2 Needlesticks

Needlestick

Needlestick

Needlestick

Needlestick

Cut with sharp

object

Cutaneous ${ }^{\star \star \star}$

Nonintact skin

Mucous-membrane

Nonintact skin

Needlestick

Mucous membrane

Needlestick

Needlestick

Cut with sharp

object
Source

AIDS patient

AIDS patient

AIDS patient

AIDS patient HIVinfected patient

AIDS patient

AIDS patient

HIV-infected patient

AIDS patient

Concentrated virus

AIDS patient

AIDS patient

HIV-infected patient

HIV-infected patient

AIDS patient

HIV-infected patient

AIDS patient

AIDS patient

AIDS patient

* AIDS care

** Not specified

*** Mother who provided nursing care for her child with HIV infection; extensive contact with the child's blood and body secretions and excretions occurred; the mother did not wear gloves and often did not wash her hands immediately after exposure. 